\title{
Genetic diversity and occurrence of the F129L substitutions among isolates of Alternaria solani in south-eastern Sweden
}

\author{
Firuz Odilbekov*, Eva Edin², Larisa Garkava-Gustavsson ${ }^{3}$, Helena Persson Hovmalm³ and Erland Liljeroth ${ }^{1}$
}

\begin{abstract}
Background: Early blight, caused by the fungus Alternaria solani, occurs on potato mainly in the south-eastern part of Sweden, but also in other parts of the country. The aim of this study was to investigate the genetic diversity of A. solani populations from different potato growing regions in south-eastern Sweden using AFLP marker analysis. In addition, the cultured isolates were examined for substitutions in the gene encoding cytochrome $b$, associated with loss of sensitivity against Qol fungicides.

Results: Nei's gene diversity index for the Swedish populations of A. solani revealed a gene diversity of up to 0.20. Also genetic differentiation was observed among populations of $A$. solani from different locations in south-eastern Sweden. The mitochondrial genotype of the isolates of $A$. solani was determined and both known genotypes, $\mathrm{Gl}$ (genotype 1) and GII (genotype 2), were found among the isolates. The occurrence of the F129L substitution associated with a loss of sensitivity to strobilurins was confirmed among the Gll isolates. In vitro conidial germination tests verified that isolates containing the F129L substitution had reduced sensitivity to azoxystrobin and, at a lower extent, to pyraclostrobin.
\end{abstract}

Conclusions: Genetic diversity was relatively high among isolates of A. solani in south-eastern part of Sweden. F129L substitutions, leading to reduced sensitivity to strobilurins, have been established in field populations, which may have implications for the future efficacy of Qol fungicides.

Keywords: AFLP, Early blight, Potato, Strobilurin, Sensitivity

\section{Background}

Several fungal species within the genus Alternaria are known as destructive plant pathogens [1] causing severe damage leading to economic losses for growers. Alternaria solani is an asexual plant pathogenic species that causes early blight on potato (Solanum tuberosum L.), and other members of the Solanaceae family. The disease may result in large crop losses in many potato and tomato producing areas worldwide [2]. The pathogen mostly infects the foliage and produces dark brown lesions with concentric rings that enlarge, coalesce and eventually cause leaf death [3]. The fungus may also infect tubers during storage in some areas, but relatively little research has been carried out on tuber diseases caused by Alternaria sp. [4, 5].

\footnotetext{
* Correspondence: firuz.odilbekov@slu.se

${ }^{1}$ Department of Plant Protection Biology, Swedish University of Agricultural

Sciences, P.O. Box 102, SE-230 53 Alnarp, Sweden

Full list of author information is available at the end of the article
}

Early blight is a common fungal disease in Swedish potato fields and during the last decade a number of reports have stressed that the disease is an increasing problem in the south-eastern part of the country, especially in starch potato crops. Both $A$. solani and $A$. alternata have been detected in the field, but $A$. solani was found more often [6]. Further investigations confirmed that early blight in south-eastern Sweden is mainly caused by $A$. solani [7].

Effectiveness of host resistance and fungicide application can, to a great extent, be influenced by the genetic variation of pathogens [8]. Therefore, to improve plant disease management, knowledge about the genetic structure of the pathogen population should be taken into consideration [9]. Several studies point towards high genetic variation among isolates of $A$. solani, even though it is considered as an asexually reproducing fungus. Isozyme analyses revealed high genetic variation among 
isolates of $A$. solani from both potato and tomato in the USA [10] and this was subsequently confirmed using RAPD marker analysis [11]. Similarly, high genetic variability among South African isolates obtained from potato was observed by population analysis using random amplified microsatellite markers (RAMS) [12] and among Chinese isolates from potato using Amplified fragment length polymorphism (AFLP) fingerprints [13]. However, in Sweden and other Nordic countries no studies of A. solani populations have been reported.

AFLP remains a powerful and highly reproducible PCR-based technique for DNA-fingerprinting. Since this method does not require prior knowledge of genomic sequence and produces large number of polymorphic loci, it is still one of the most commonly used PCR based methods for genetic diversity analysis. This method has been used in several studies of genetic diversity in Alternaria species $[9,13,14]$.

The most common way of controlling early blight in Swedish potato production today is to treat the crop with Qol fungicides (strobilurins). This method has so far been efficient in controlling early blight [6]. However, strobilurins have been reported to show reduced efficacy against species of Alternaria in some parts of the USA [15-18]. Strains of A. solani that display reduced sensitivity to strobilurins have nucleotide substitutions in the amino acid codon at position 129 (referred to as F129L, phenylalanine has changed to leucine) in the gene encoding cytochrome $b$ [17]. Recently, it has been discovered that A. solani in Europe carries two types of mitochondrial DNA. Populations carrying these two DNA types are referred to as genotype 1 (GI) and genotype 2 (GII) [19]. The latter resembles the American population of $A$. solani and can only be distinguished by PCR with special primers [15]. Analysis of Alternaria populations from Germany revealed the presence of the F129L substitution and the frequency of this substitution increased over the years [19]. Isolates that carried the F129L substitution had reduced in vitro sensitivity to Qol fungicides. In Sweden, observations of reduced field efficacy of strobilurins have been reported during the last few years, especially in the area around Kristianstad (personal communication with growers, advisors and the Swedish Board of Agriculture).

The objectives of the present study were to: 1 ) examine the genetic diversity within and among populations of $A$. solani from two potato growing regions in south-eastern Sweden by applying AFLP marker analysis; 2) examine the cultured isolates for substitutions in the gene encoding cytochrome $b$ that are associated with a loss of sensitivity to stroilurins.

\section{Methods}

\section{Collection, isolation and identification of fungal cultures}

Leaflets with symptoms resembling early blight were collected in starch potato fields in two regions (Kalmar/Öland and Kristianstad) of South-eastern Sweden during September 2011. Two fields were sampled in the Kalmar/Öland region and three in the vicinity of Kristianstad (Fig. 1). The sampling was performed in four rows with eight rows in between. In each row, samples were collected at six points, approximately $10 \mathrm{~m}$ apart. The leaflets were placed in small paper bags and air dried. The sampled fields had been treated at least once with strobilurins, either in the second or the fourth week of July, prior to sampling. The majority of the fields were treated twice.

Sections 3-4 $\mathrm{mm}$ around the edge of lesions were cut and surface sterilized in $1 \%$ sodium hypochlorite for $3 \mathrm{~min}$ followed by two times washing in sterile distilled water. The leaf discs were placed on water agar containing a broad-spectrum antibiotic (chlorotetracycline, $100 \mu \mathrm{g} \mathrm{mL}^{-1}$ ) and stored in darkness at room temperature for 3-4 days. Single conidium was picked directly from the infected leaf tissue with a tiny needle under a stereo-microscope and placed on new potato dextrose agar for germination. Species identification was performed morphologically and identifications of $A$. solani were confirmed with PCR based methods $[18,20]$. In addition all isolates were also checked with specific primers developed for the closely related species $A$. tomatophila [21]. All reactions were performed in duplicates with a positive and a negative control. The primers for identification of $A$. solani GI [20] amplify both genotypes but the PCR-product of GII is shorter and the normal amino acid codon sequence around position 129 is absent. Fifty-five isolates of $A$. solani representing different regions, fields and rows within fields (three isolates per row from four rows per field) were selected for analysis (Table 1). Four isolates of $A$. alternata from Sweden were included in the UPGMA analysis as comparison (see below).

\section{DNA extraction}

For DNA extraction, each isolate was grown in a liquid medium containing $10 \mathrm{gL}^{-1}$ of sucrose, $2 \mathrm{gL}^{-1}$ of L-asparagin, $2 \mathrm{gL}^{-1}$ of yeast extract, $15 \mathrm{mM} \mathrm{KH}_{2} \mathrm{PO}_{4}$,

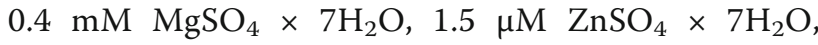
$1.8 \mu \mathrm{M} \mathrm{FeCl} \mathrm{F}_{3} \times 6 \mathrm{H}_{2} \mathrm{O}$, and $2.5 \mu \mathrm{M} \mathrm{MnCl} \mathrm{M}_{2} \times \mathrm{H}_{2} \mathrm{O}$ in Erlenmeyer flasks under continuous agitation $(60 \mathrm{rpm})$ at room temperature [22]. After eight days, the mycelium was washed with sterile distilled water, transferred to filter paper and freeze dried. Genomic DNA Purification Kit (Fermentas Lithuania) was used to extract the total genomic DNA. Depending on the size of the DNA pellet, 30 to $50 \mu \mathrm{L}$ of $\mathrm{ddH}_{2} \mathrm{O}$ with RNase was added and the pellet was re-suspended at $37^{\circ} \mathrm{C}$ for $2 \mathrm{~h}$ and subsequently stored at $4{ }^{\circ} \mathrm{C}$. The quality of DNA was determined by electrophoresis using $1 \%$ agarose gel containing ethidium bromide and the final concentration was adjusted to $100 \mathrm{ng} / \mu \mathrm{l}$ using a Nanodrop ${ }^{\circ}$ ND-1000 spectrophotometer (NanoDrop Technologies, Inc. DE, USA). 


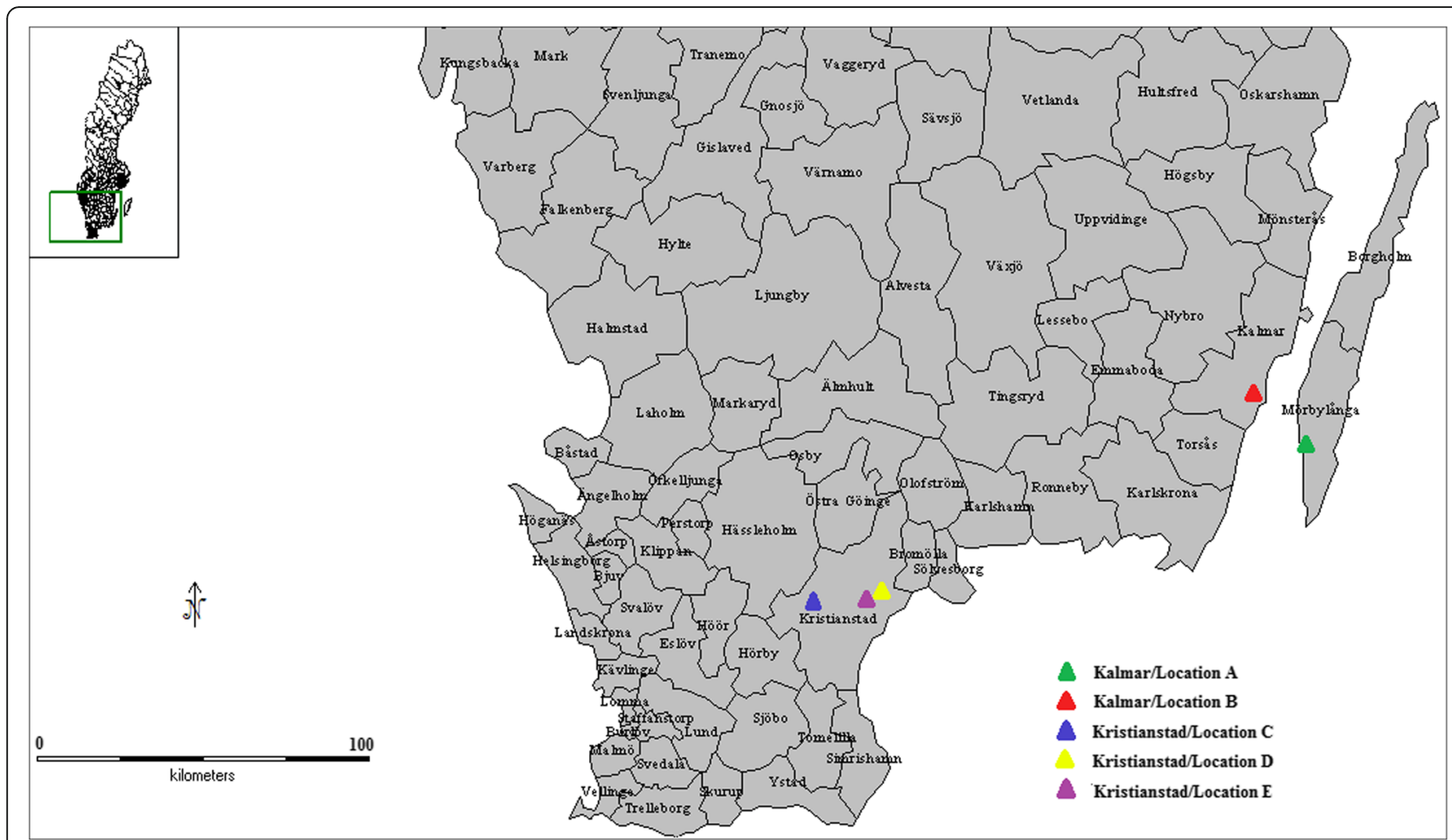

Fig. 1 Map of southern Sweden showing the location where the isolates of Alternaria solani were sampled

\section{AFLP analysis}

The AFLP analysis was performed using an AFLP Microbial Fingerprinting Kit (Applied Biosystems, CA, USA) based on a modified manufacturer's protocol [23]. Genomic DNA of each isolate was digested with two restriction enzymes (EcoRI and MseI), ligated to oligonucleotide adapters and pre-amplification was performed. The selective amplification was performed using seven labelled primer combinations: $\mathrm{E}+\mathrm{ACM}+\mathrm{A}, \mathrm{E}+\mathrm{ACM}+\mathrm{G}$, $\mathrm{E}+\mathrm{ACM}+\mathrm{C}, \mathrm{E}+\mathrm{AAM}+\mathrm{A}, \mathrm{E}+\mathrm{AAM}+\mathrm{G}, \mathrm{E}+\mathrm{AAM}+\mathrm{C}$ and $\mathrm{E}+\mathrm{AT} / \mathrm{M}+\mathrm{A}$ [9]. The main amplified $\mathrm{PCR}$ products were multiplexed into panels using different fluorescent labels and analysed on an ABI 3730 capillary DNA analyser (Applied Biosystems) at the University of Copenhagen, Denmark. The results were visualized and analysed using Genemarker (Softgenetics ${ }^{\oplus}$, PA, USA). Each individual band was scored manually using both the gel image and the peak height. In both cases, default settings in Genemarker were applied for detection of bands with the recommended threshold intensity of 100 . Bands between 60 and 500 base pairs were scored as either present " 1 " or absent " 0 ". Only bands that could be scored unambiguously were included in the AFLP analysis.

\section{Data analysis}

Genetic diversity was calculated by the number and percentage of polymorphic loci, Shannon's information index (I) and Nei's gene diversity $(\mathrm{H})$. For each population,
Nei's gene diversity $(\mathrm{H})$ and Shannon's index (I) were calculated for each locus and then averaged over all loci. Calculations of these parameters were performed using POPGENE version 1.32. A dendrogram was obtained by cluster analysis of all isolates using the unweighted pair group method with arithmetic means (UPGMA) [24], similarity coefficient (SAHN procedure in the NTSYS pc 2.2 statistical package). The FreeTree software [25] was applied for statistical support of dendrogram branches with 1000 bootstrapping samples. Principal coordinate analysis (PCoA) was performed to obtain a graphic representation of the relationship among the 52 isolates of $A$. solani, since some of the isolates did not give any results. Calculations were made using the procedures in the NTSYS pc 2.2 statistical package. Analysis of molecular variance (AMOVA) was carried out by using Arlequin 3.0 [26]. The number of permutations for significance tests was set at 1000 for all analyses.

\section{Cytochrome $\boldsymbol{b}$ substitutions}

To detect any substitution in the gene encoding cytochrome $b$ associated with loss of sensitivity to strobilurins, the region was amplified using PCR and then sequenced. DNA from all samples determined as A. solani was amplified using specific primers. For the GI genotype the procedure of Edin [20] was followed and for the GII genotype primers developed by Pasche et al. [15] were used for the PCR amplifications. The PCR solution of $50 \mu \mathrm{l}$ contained 
Table 1 Geographic origin and mitochondrial genotype of the Alternaria solani isolates used in this study

\begin{tabular}{|c|c|c|c|c|c|c|c|}
\hline No & Species & Geographic region & Location & Gl & Gll & $\mathrm{GI}^{\mathrm{a}}$ & Abbreviation \\
\hline 1 & A. solani & Kalmar & $A$ & - & + & - & ASKLA1 \\
\hline 2 & A. solani & Kalmar & $A$ & + & - & - & ASKLA2 \\
\hline 3 & A. solani & Kalmar & A & + & - & - & ASKLA3 \\
\hline 4 & A. solani & Kalmar & A & + & - & - & ASKLA4 \\
\hline 5 & A. solani & Kalmar & A & n.d & n.d & n.d & ASKLA5 \\
\hline 6 & A. solani & Kalmar & A & - & + & - & ASKLA6 \\
\hline 7 & A. solani & Kalmar & $A$ & - & + & - & ASKLA7 \\
\hline 8 & A. solani & Kalmar & A & + & - & - & ASKLA8 \\
\hline 9 & A. solani & Kalmar & A & + & - & - & ASKLA9 \\
\hline 10 & A. solani & Kalmar & A & - & + & - & ASKLA10 \\
\hline 11 & A. solani & Kalmar & A & + & - & - & ASKLA11 \\
\hline 12 & A. solani & Kalmar & A & + & & - & ASKLA12 \\
\hline 13 & A. solani & Kalmar & B & - & + & - & ASKLB1 \\
\hline 14 & A. solani & Kalmar & B & + & - & - & ASKLB2 \\
\hline 15 & A. solani & Kalmar & B & + & - & - & ASKLB3 \\
\hline 16 & A. solani & Kalmar & B & + & - & - & ASKLB4 \\
\hline 17 & A. solani & Kalmar & B & + & - & - & ASKLB5 \\
\hline 18 & A. solani & Kalmar & B & + & - & - & ASKLB6 \\
\hline 19 & A. solani & Kalmar & B & + & - & - & ASKLB7 \\
\hline 20 & A. solani & Kalmar & B & + & - & - & ASKLB8 \\
\hline 21 & A. solani & Kalmar & B & + & - & - & ASKLB9 \\
\hline 22 & A. solani & Kalmar & B & + & - & - & ASKLB10 \\
\hline 23 & A. solani & Kalmar & B & + & - & - & ASKLB11 \\
\hline 24 & A. solani & Kalmar & B & + & - & - & ASKLB12 \\
\hline 25 & A. solani & Kristianstad & $C$ & n.d & n.d & n.d & ASKRLC1 \\
\hline 26 & A. solani & Kristianstad & C & + & - & - & ASKRLC2 \\
\hline 27 & A. solani & Kristianstad & C & + & - & - & ASKRLC3 \\
\hline 28 & A. solani & Kristianstad & C & + & - & - & ASKRLC4 \\
\hline 29 & A. solani & Kristianstad & C & + & - & - & ASKRLC5 \\
\hline 30 & A. solani & Kristianstad & C & - & + & - & ASKRLC6 \\
\hline 31 & A. solani & Kristianstad & C & n.d & n.d & n.d & ASKRLC7 \\
\hline 32 & A. solani & Kristianstad & C & + & - & - & ASKRLC8 \\
\hline 33 & A. solani & Kristianstad & C & + & - & - & ASKRLC9 ${ }^{b}$ \\
\hline 34 & A. solani & Kristianstad & C & + & - & - & ASKRLC10 \\
\hline 35 & A. solani & Kristianstad & $C$ & + & - & - & ASKRLC11 \\
\hline 36 & A. solani & Kristianstad & C & + & - & - & ASKRLC12 \\
\hline 37 & A. solani & Kristianstad & D & - & - & + & ASKRLD1 \\
\hline 38 & A. solani & Kristianstad & $D$ & - & - & + & ASKRLD2 \\
\hline 39 & A. solani & Kristianstad & $D$ & - & - & + & ASKRLD3 $^{b}$ \\
\hline 40 & A. solani & Kristianstad & $D$ & - & - & + & ASKRLD4 \\
\hline 41 & A. solani & Kristianstad & $D$ & n.d & n.d & n.d & ASKRLD5 \\
\hline 42 & A. solani & Kristianstad & D & - & - & + & ASKRLD $^{\mathrm{b}}$ \\
\hline 43 & A. solani & Kristianstad & $D$ & n.d & n.d & n.d & ASKRLD7 \\
\hline 44 & A. solani & Kristianstad & $D$ & - & - & + & ASKRLD8 \\
\hline
\end{tabular}


Table 1 Geographic origin and mitochondrial genotype of the Alternaria solani isolates used in this study (Continued)

\begin{tabular}{|c|c|c|c|c|c|c|c|}
\hline 45 & A. solani & Kristianstad & $D$ & - & - & + & ASKRLD9 \\
\hline 46 & A. solani & Kristianstad & $D$ & - & - & + & ASKRLD10 \\
\hline 47 & A. solani & Kristianstad & $D$ & - & - & + & ASKRLD11 \\
\hline 48 & A. solani & Kristianstad & $D$ & - & - & + & ASKRLD12 \\
\hline 49 & A. solani & Kristianstad & $E$ & + & - & - & ASKRLE1 \\
\hline 50 & A. solani & Kristianstad & $E$ & n.d & n.d & n.d & ASKRLE2 \\
\hline 51 & A. solani & Kristianstad & $E$ & + & - & - & ASKRLE3 \\
\hline 52 & A. solani & Kristianstad & $E$ & + & - & - & ASKRLE4 \\
\hline 53 & A. solani & Kristianstad & $E$ & + & - & - & ASKRLE5 \\
\hline 54 & A. solani & Kristianstad & $E$ & n.d & n.d & n.d & ASKRLE6 \\
\hline 55 & A. solani & Kristianstad & $E$ & + & - & - & ASKRLE7 \\
\hline
\end{tabular}

Gl genotype I, GII genotype II, a genotype II with F129L substitution, ${ }^{\text {b }}$ not included in diversity study, n.d not determined

0.25 ng DNA $\mu \mathrm{L}^{-1}, 0.75 \mathrm{mM} \mathrm{MgCl}_{2}$ (final concentration),

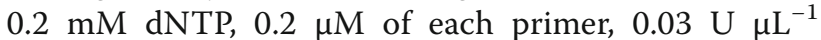
ThermoRed DNA Polymeras (Saveen \& Werner AB) and corresponding reaction buffer. The PCR conditions were $96{ }^{\circ} \mathrm{C}$ for $5 \mathrm{~min}, 40$ cycles of $30 \mathrm{~s}$ at $96^{\circ} \mathrm{C}, 30 \mathrm{~s}$ at $60{ }^{\circ} \mathrm{C}(\mathrm{GI})$ or $54{ }^{\circ} \mathrm{C}(\mathrm{GII})$ and $30 \mathrm{~s}$ at $72{ }^{\circ} \mathrm{C}$, followed by a 5 min extension. The success of the PCR amplifications was analysed using electrophoresis (1\% agarose gel stained with Nancy-250 (Sigma-Aldrich, MO USA). The products were purified using Agencourt AMPure XP (Beckman Coulter, MA, USA) according to the manufacturer's protocol and sequenced at Macrogen Inc. Seoul, South Korea. The procedures were repeated for those isolates with conflicting results.

\section{In vitro sensitivity assay}

Azoxystrobin and pyraclostrobin (analytical standard, Sigma) were dissolved in $1 \mathrm{~mL}$ acetone to a concentration of $100 \mathrm{mg} \mathrm{mL}^{-1}$ and used as stock solution. Petri dishes with water agar containing different concentrations of azoxystrobin or pyraclostrobin (0, 0,01 $0,1 \quad 1$ and $10 \mu \mathrm{g} \mathrm{mL}^{-1}$ ) were prepared. The agar also contained $100 \mathrm{mg} \mathrm{L}^{-1}$ salicylhydroxamic acid (SHAM). Petri dishes with SHAM but no azoxystrobin/pyraclostrobin were used as a control. The final concentration of acetone in all media was $0.1 \%(v / v)$. Spores of $A$. solani were produced [27] and the spore suspension was adjusted to $2 \times 10^{4}$ conidia $\mathrm{mL}^{-1}$. Fifty microliters of conidial suspension of each isolate was spread across the agar plates, containing different concentrations of azoxystrobin/pyraclostrobin (two replicate plates) and on control plates (two replicate plates). Plates were incubated in a growth chamber at a temperature of $28{ }^{\circ} \mathrm{C}$ under continuous light for $5 \mathrm{~h}$ and germination of 100 conidia was evaluated microscopically at $100 \mathrm{x}$ magnification. For each isolate, the concentration that effectively inhibited germination of $50 \%$ of the conidia relative to the untreated control $\left(\mathrm{EC}_{50}\right)$ was calculated. Then the plates were incubated again for another
$10 \mathrm{~h}$ (in total, $15 \mathrm{~h}$ ) and the germination rate was measured again. Five wildtype isolates and five isolates with F129L substitution from 2011 were evaluated and the test was repeated once. In addition, ten isolates with F129L substitution obtained from Kristianstad location $\mathrm{E}$ in 2014 were evaluated as comparison.

\section{Results}

\section{Genetic diversity}

In total, 271 AFLP bands were observed using the seven selected primer combinations and close to $100 \%$ of the bands produced were polymorphic (Table 2). The degree of polymorphism for $A$. solani isolates ranged from 36.2 to $98.4 \%$. The primer combinations $\mathrm{E}+\mathrm{AA} / \mathrm{M}+\mathrm{A}, \mathrm{E}+$ $\mathrm{AA} / \mathrm{M}+\mathrm{C}$ and $\mathrm{E}+\mathrm{AT} / \mathrm{M}+\mathrm{A}$ gave higher percentages of polymorphism in $A$. solani compared to the other primer combinations (Table 2).

A comparison of the Nei's gene diversity index for the five Swedish populations of $A$. solani revealed that the

Table 2 Number of amplified AFLP fragments and degree of polymorphism among isolates of Alternaria solani with different EcoRI/Msel primers

\begin{tabular}{lll}
\hline $\begin{array}{l}\text { Primer } \\
\text { combination }\end{array}$ & $(n=52)$ & $\%$ pol \\
\cline { 2 - 3 } & Total $^{\mathrm{a}}$ & 94,4 \\
$E+A A M M+A$ & 68 & 98,4 \\
$E+A A M M+C$ & 61 & 83,6 \\
$E+A A M+G$ & 46 & 70,4 \\
$E+A C / M+A$ & 31 & 36,2 \\
$E+A C / M+C$ & 17 & 42,1 \\
$E+A C / M+G$ & 16 & 91,4 \\
$E+A T / M+A$ & 32 & 73,8 \\
\hline Total & 271 &
\end{tabular}

aTotal number of fragments observed

${ }^{\mathrm{b}}$ Percentage of total fragments that were polymorphic 
gene diversity was lowest in the Kristianstad/location D population (0.080) and highest in the Kalmar/location A population (0.182) (Table 3). Also for the Shannon's index, Kristianstad/location D had the lowest value (0.120) whereas Kalmar/location A had the highest (0.273). Comparisons between the two Swedish regions revealed that the Kalmar region had a higher level of diversity than the Kristianstad area.

UPGMA cluster analysis (see dendrogram; Fig. 2) clearly separated the two species into two main clusters. This separation was supported by a high bootstrap value (100\%). There were two distinct sub-clusters of $A$. solani isolates within cluster 2 in $100 \%$ of the 1000 bootstrapped trees. The first sub-cluster (2.1) consisted of 44 isolates from all five locations. Isolates from Kristianstad/location D grouped together but with poor statistical support. Subcluster 2.2 comprised eight $A$. solani isolates, including seven isolates from Kalmar/location A and one isolate from Kristianstad/location C. The Kalmar/location A was the only field where the isolates were highly separated genetically.

Principal coordinates analysis was performed to further evaluate relatedness among the $A$. solani isolates. The first three principal components explained 28, 9.6 and $6 \%$ of the total variation, respectively. Thus, the three-dimensional plot (Fig. 3) summarizes $43.6 \%$ of the total variation in all $A$. solani isolates. Isolates from Kristianstad/location D grouped more closely together in this analysis compared to the UPGMA, which indicates high genetic similarity of the isolates from this location. All isolates, except one, from Kalmar/location B also grouped closely together. AMOVA was used to partition the total genetic variance within and among population components (Table 4). The percentage of variation among populations was $20 \%$ (Fst $=0,20, P<0.0001$ ) and a much higher proportion of variation was observed within populations $(80 \%)$.

Table 3 Gene diversity estimators for populations of Alternaria solani from different regions in Sweden based on results of seven amplified fragment length polymorphism (AFLP) primer pair combinations

\begin{tabular}{llllll}
\hline All location & NI & NPL & PPL & H & I \\
\hline Kalmar/Location A & 12 & 180 & 51,0 & 0,182 & 0,273 \\
Kalmar/Location B & 12 & 175 & 49,6 & 0,155 & 0,238 \\
Kristianstad/Location C & 11 & 195 & 55,2 & 0,167 & 0,260 \\
Kristianstad/Location D & 10 & 81 & 23,0 & 0,080 & 0,120 \\
Kristianstad/Location E & 7 & 140 & 39,7 & 0,151 & 0,223 \\
All Kalmar locations & 24 & 244 & 69,1 & 0,206 & 0,317 \\
All Kristianstad locations & 28 & 219 & 62,0 & 0,166 & 0,259 \\
\hline
\end{tabular}

$N /$ number of isolates, $N P L$ number of polymorphic loci, PPL percentage of polymorphic loci, $H$ Nei's gene diversity, I Shannon's information index

\section{Cytochrome $b$ mutants and sensitivity test}

Both genotypes, GI and GII, were found in three out of five fields (Table 1). None of the GI genotypes carried the F129L substitution, while the majority of the GII isolates did. Four wild type GII isolates were found at location A in Kalmar, while a single wild type GII isolate was found at location B in Kalmar and location C in Kristianstad, respectively. At location D in Kristianstad, all ten investigated isolates were GII with the F129L substitution. This was the only field where F129L substitution was found 2011. However, in 2014 isolates carrying F129L were also found in Kristianstad location E.

All A. solani isolates with the F129L substitution tested in vitro were less sensitive to azoxystrobin (Fig. 4). Means of $\mathrm{EC}_{50}$ values, based on germination rates $5 \mathrm{~h}$ after inoculation for isolates from 2011 and 2014 that contained the substitution were $0.7-0.9 \mu \mathrm{g} \mathrm{mL}^{-1}$ respectively, while the mean of the wild type isolates was $0.07 \mu \mathrm{g} \mathrm{mL}^{-1}$. Overall, comparing mean $\mathrm{EC}_{50}$ values, wild type isolates were 10-fold more sensitive compared to isolates containing F129L substitution from 2011 and 13-fold more sensitive in comparison to isolates from 2014 (Fig. 4). The shift to reduced sensitivity was less pronounced with pyraclostrobin compared to azoxystrobin and wild type isolates from 2011 were 2-fold more sensitive to pyraclostrobin than isolates with the F129L substitution (Fig. 4). However, a much higher degree of differentiation in sensitivity between wildtype and mutants was found $15 \mathrm{~h}$ after inoculation at concentrations $0.1,1$ and $10 \mu \mathrm{g} \mathrm{mL}^{-1}$ (Table 5).

\section{Correlation between genetic structure, mitochondrial genotype and presence of cytochrome $b$ mutants}

In general, there was no obvious correlation between the geographical origin of the $A$. solani isolates and the genetic structure. However, in one location, Kristianstad D, all the isolates were GII with the F129L substitution and they grouped closely together in the PCoA plot (Fig. 3). The isolates from the other populations were scattered in the PCoA and showed no clear pattern of correlation between mitochondrial genotype and genetic structure. There was no correlation between mitochondrial genotype and clustering (Fig. 2).

\section{Discussion}

The level of genetic diversity among isolates of $A$. solani from South-eastern Sweden was found to be relatively high for a species assumed to only have asexual reproduction. Previous studies of these species have shown genetic distinctness between populations of $A$. solani and $A$. alternata infecting potato [10] and both tomato and potato in the USA [11], Cuba [14] and Brazil [9]. The level of diversity in A. solani was slightly lower compared to the previously mentioned studies as indicated by the diversity indexes in the present study. 


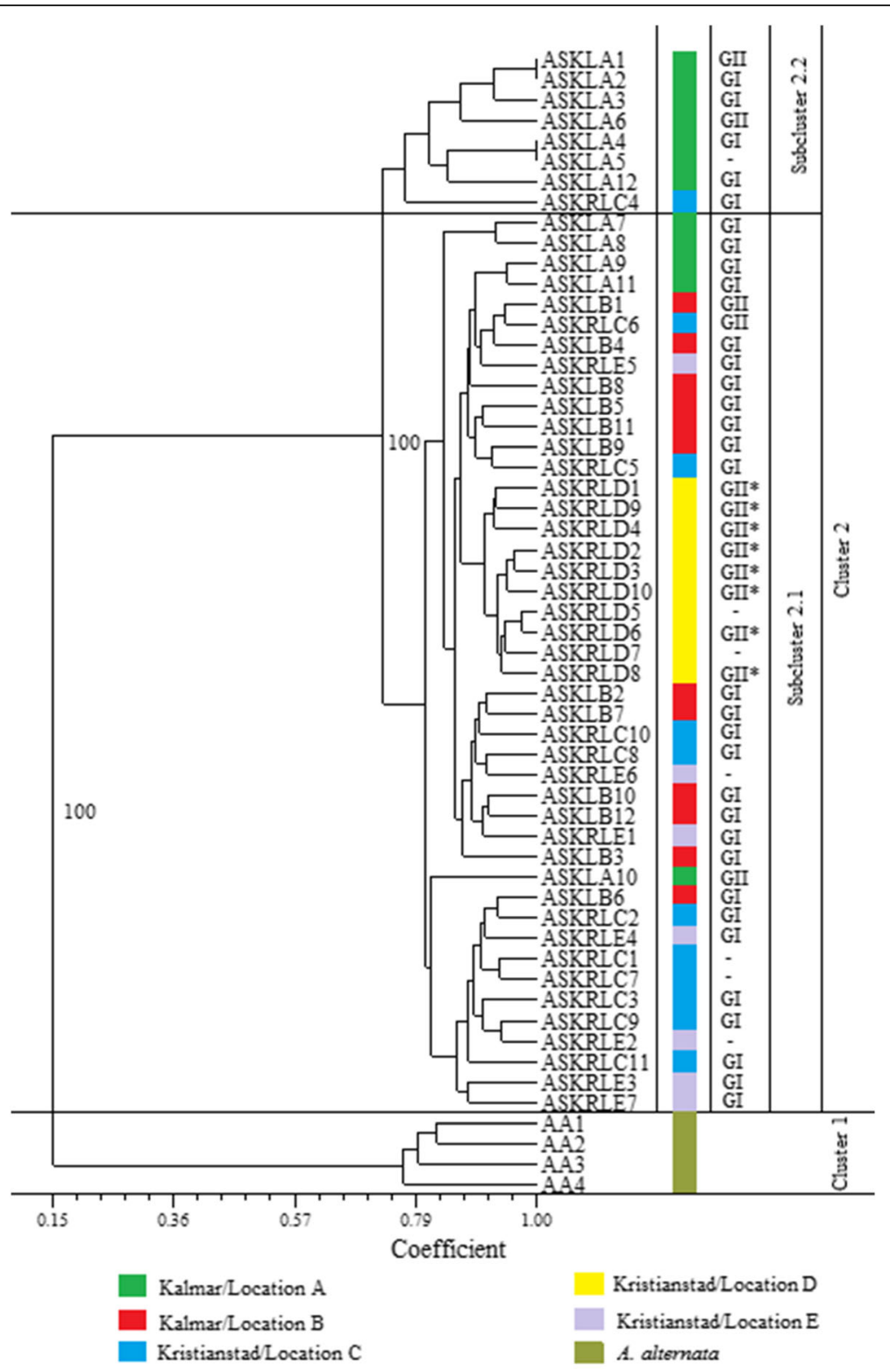

Fig. 2 Dendrogram from cluster analysis (UPGMA) based on Dice genetic similarity for Alternaria solani isolates from Sweden. The values at the branches are the bootstrap values generated by 1000 re-samplings. The colour shows different locations where the samples were collected. $\mathrm{Gl}$ = genotype I, GII = genotype II, G $\|^{*}=$ genotype $\|$ with F129L substitution. A few A. alternata isolates were included as an outgroup

A possible explanation could be that other studies used isolates from different Solanaceous hosts while we investigated only samples from potato. Different results may also be due to different sample sizes.

Both mitochondrial genotypes as well as the F129L substitution in the cyt $b$ gene occur within $A$. solani populations in Sweden. In Europe, A. solani isolates containing the F129L substitution were first found in Germany. Isolates possessing the substitution also displayed a shift in sensitivity to different strobilurins in in vitro spore germination assays [19]. None of the Swedish GI isolates carried the F129L substitution, while the F129L substitution was observed in many of the GII isolates. Results from the present study revealed that isolates carrying the F129L substitution exhibited a reduction in sensitivity to azoxystrobin as well as to pyraclostrobin in in vitro spore germination tests (Fig. 4). The shift to reduced sensitivity also tended to be more pronounced in isolates with the F129L substitution collected in 2014 compared to isolates from 2011, indicating that application of QoI fungicides has resulted in reduced sensitivity of the isolates over time. These results are in accordance with the previous study [19], which also reported that isolates carrying this substitution had 


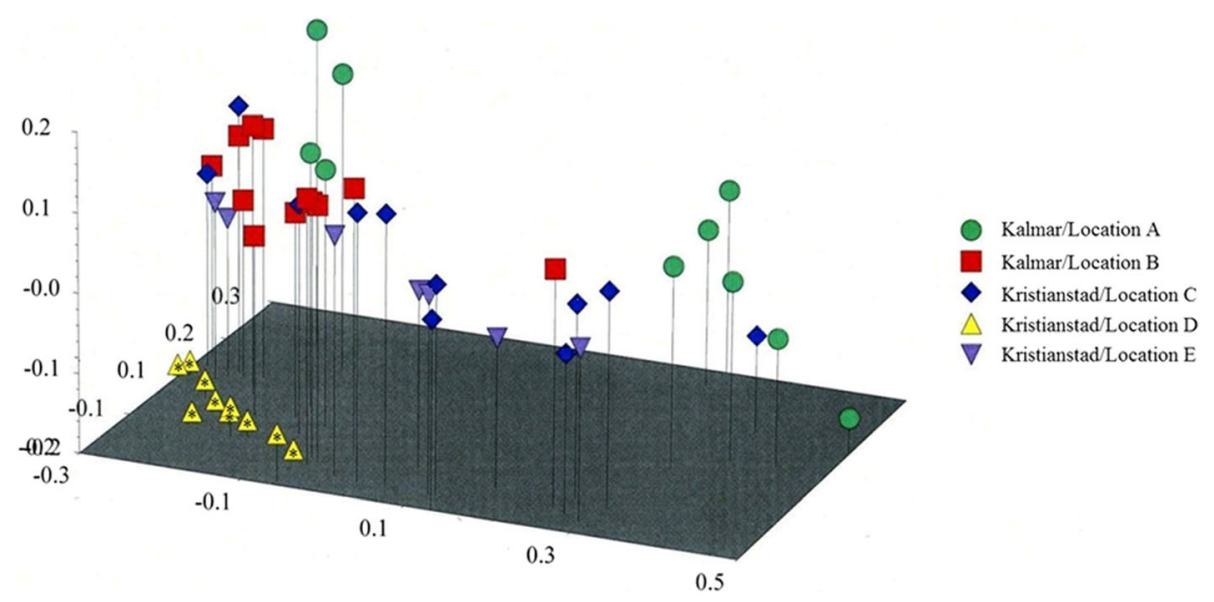

Fig. 3 Principal coordinate analysis (PCOA) of 52 isolates of Alternaria solani from five locations in Sweden based on AFLP data. ${ }^{*}=\mathrm{Gll}$ with F129L mutation

reduced in vitro sensitivity to QoI fungicides, especially against azoxystrobin.

$\mathrm{EC}_{50}$ values are commonly calculated based on spore germination rates at $5 \mathrm{~h}$ after inoculation. However, we found a better differentiation between the wildtype and isolates harboring the F129L substitution after $15 \mathrm{~h}$. At the highest concentrations there was a clear difference in germination rate (Table 5). In addition, a field trial during 2014 clearly showed that significant disease control was not obtained by using azoxystrobin only against early blight (unpublished).

There was a significant genetic differentiation (Fst = $0.200, P<0.0001$ ) among the $A$. solani populations from the different locations. UPGMA sub-cluster 2.2 that deviated from the other A. solani clusters (Fig. 2) was dominated by isolates from Kalmar location A, suggesting that part of the population on the island in the Kalmar region is genetically different. Fst values between 0.15 and 0.25 reportedly represent moderately high genetic differentiation [28]. The mitochondrial DNA and genomic DNA did not have any apparent correlation, since the F129L locus was not associated with any specific AFLP-locus and both genotypes, GI and GII, were found in all clusters. In one of the Kristianstad locations (location D) A. solani isolates that carried the F129L substitution grouped closely together (Fig. 3). However, in the other clusters, isolates from different locations grouped together indicating that migration may have taken place.

Alternaria solani is not known to undergo sexual recombination. However, genetic recombination in different putatively asexual fungal populations has been reported [29-32]. According to [29-32], these fungi may have an alternative mechanism for promoting recombination of genomes. Recombination events within A. alternata subpopulations were observed suggesting that a non-meiotic mechanism of recombination, i.e. a parasexual cycle, may be operating [32]. Cytological and morphological studies suggested that heterokaryosis could occur in A. solani [33]. Heterokaryosis can be preserved or lost during further cell divisions. Also nuclear migration could occur through septal pores between cells of conidia, conidiophores and mycelia, allowing dissociation of unlike nuclei leading to homokaryosis, or re-establishment of heterokaryosis [33]. Therefore, even isolates from single conidia or hyphal tips could be genetically diverse.

Another possible explanation for the high level of genetic variation among the isolates, including the presence of F129L, is natural mutations that occur spontaneously. The pathogen produces abundant numbers of spores in a relatively short period of time, and mutations may play an important role in generating diversity $[10,12,34]$. Natural mutations may occur more frequently in asexually reproducing isolates than in sexually reproducing ones [35]. Several studies have reported mutations in A. solani populations in the USA, especially in mitochondrial DNA $[15,36]$ and in Germany [19]. The high usage of fungicides most likely explains why the genetically diverse populations have the same mutation. The mutation is being strongly selected for. However, to quantify the mutation rate within $A$. solani the complete genome of the species must be sequenced.

Table 4 Analysis of molecular variances among the investigated populations of Alternaria solani in Sweden

\begin{tabular}{lllclll}
\hline Source of variation & d.f & Sum of squares & Variance components & Variation (\%) & Fst & Probability \\
\hline Among Populations & 4 & 416 & $7.27 \mathrm{Va}$ & 20 & 0.20 & Va and Fst $=0.0000$ \\
Within populations & 47 & 1366 & $29.0 \mathrm{Vb}$ & 80 & & \\
\hline
\end{tabular}




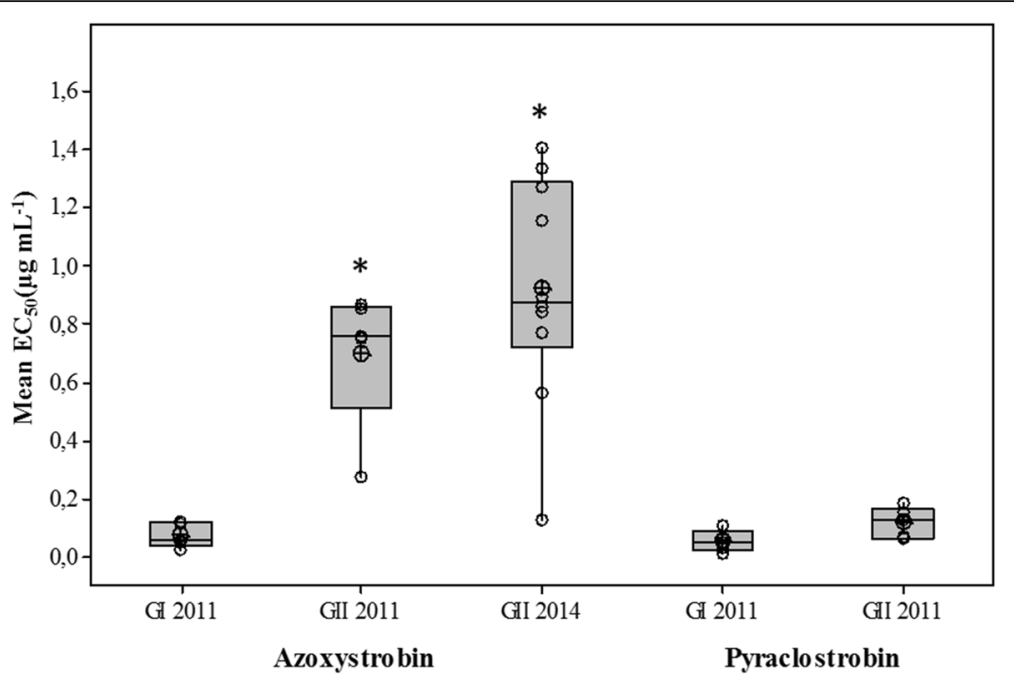

Fig. 4 Mean of $\mathrm{EC}_{50}$ values for wild type (GI) $(n=5,2011)$ and F129L substitution isolates (GII) $(n=5,2011$ and $n=10$, 2014) of Alternaria solani obtained from in vitro sensitivity tests of azoxystrobin and pyraclostrobin after $5 \mathrm{~h}$ incubation. ${ }^{*}=$ significantly different from wild type $2011(p<0.05)$ according to two sample t-tests using Minitab 16.2.4 statistical software

Understanding the genetic diversity of $A$. solani is a base for optimizing disease management strategies against early blight. Further genetic studies on the pathogen involving sampling of a larger number of (sub)-populations covering a wider geographic range would enhance our understanding of population structure, levels of genetic variation and migration patterns in Sweden and elsewhere.

In practical agriculture, fungicide resistance is one of the main problems with chemical pest management, and one that has become an issue in the control of Alternaria spp. As a result of the frequent applications of QoI fungicides in potato fields in USA [17] and Germany [19] $A$. solani isolates with reduced sensitivity to strobilurins have

Table 5 In vitro sensitivity test of Alternaria solani wild type and F129L substitution isolates collected in 2011. Percentage of spores germinated after $15 \mathrm{~h}$ of incubation on media containing azoxystrobin or pyraclostrobin

\begin{tabular}{|c|c|c|c|c|c|c|c|c|c|c|c|}
\hline \multirow[t]{2}{*}{ Isolate ID } & \multirow[t]{2}{*}{ Genotype } & \multicolumn{5}{|c|}{ Azoxystrobin, $\mu \mathrm{g} / \mathrm{ml}$} & \multicolumn{5}{|c|}{ Pyraclostrobin, $\mu \mathrm{g} / \mathrm{ml}$} \\
\hline & & 0 & 0,01 & 0,1 & 1 & 10 & 0 & 0,01 & 0,1 & 1 & 10 \\
\hline ASKLA2 & $\mathrm{Gl}$ & 100 & 95 & 76 & 61 & 5 & 100 & 98 & 69 & 19 & 0 \\
\hline SKLB3 & Gl & 100 & 95 & 93 & 54 & 4 & 100 & 100 & 48 & 7 & 0 \\
\hline ASKLB4 & Gl & 100 & 96 & 73 & 9 & 0 & 100 & 97 & 21 & 1 & 0 \\
\hline ASKLB8 & Gl & 100 & 98 & 93 & 41 & 2 & 100 & 100 & 53 & 16 & 0 \\
\hline ASKLB9 & Gl & 100 & 95 & 87 & 65 & 0 & 100 & 100 & 73 & 23 & 0 \\
\hline ASKRLD1 & $\mathrm{G} \|^{a}$ & 100 & 100 & 99 & 92 & 78 & 100 & 100 & 79 & 30 & 0 \\
\hline ASKRLD2 & $\mathrm{G}\|\|^{\mathrm{a}}$ & 100 & 100 & 100 & 98 & 83 & 100 & 100 & 89 & 67 & 0 \\
\hline ASKRLD4 & $\mathrm{G} \|^{a}$ & 100 & 100 & 100 & 94 & 78 & 100 & 100 & 91 & 63 & 2 \\
\hline ASKRLD9 & $\mathrm{G} \|^{a}$ & 100 & 100 & 99 & 99 & 80 & 100 & 100 & 94 & 68 & 9 \\
\hline ASKRLD10 & $\mathrm{G} \|^{\mathrm{a}}$ & 100 & 100 & 99 & 93 & 65 & 100 & 100 & 69 & 41 & 0 \\
\hline
\end{tabular}

Isolate contains F129L substitution increased in frequency. Today, all farmers are expected to use different anti-resistance strategies, e.g. alternating fungicides with different modes of action, to prolong the effectiveness of the fungicides. Application of complex or multisite mode of action fungicides in spray programmes decreases the risk that fungicide resistance develops in the pathogen population (www.frac.info).

\section{Conclusion}

Our results provide the first insight into the level of genetic variation and the presence of F129L substitutions associated with loss of sensitivity against strobilurins among populations of $A$. solani from different locations in south-eastern Sweden. AFLP marker analysis indicates that genetic diversity among the studied isolates is relatively high and that the isolates showed a significant genetic differentiation. In addition genetic analysis of the isolates confirmed the presence of F129L substitutions, which is associated with loss of sensitivity against strobilurins.

\section{Abbreviations \\ AFLP: Amplified fragment length polymorphism; AMOVA: Analysis of molecular variance; EC50: Half maximal effective concentration; F129L: An amino acid substitution of phenylalanine with leucine at position 129; GI: Genotype 1; Gll: Genotype 2; H: Nei's gene diversity; I: Shannon's information index; NTSYS: Numerical taxonomy and multivariate analysis system; PCR: Polymerase chain reaction; Qols: Quinone outside inhibitors; UPGMA: Unweighted pair group method with arithmetic mean}

\section{Acknowledgements}

The study was financed by the Swedish International Development Agency (Sida) and the Swedish Farmer's Foundation for Agricultural Research (SLF). We are grateful to Anna Zborowska at Swedish University of Agricultural Sciences (SLU), Alnarp for skilful laboratory assistance. The authors would also like to thank Björn Andersson and Laura Grenville-Briggs for useful comments on the manuscript. 


\section{Authors' contributions}

EL designed the study; FO performed most of the lab work and analyzed the AFLP marker data, carried out all data analyses and wrote the manuscript with the advice from coauthors. EE analyzed isolates for F129L substitution; All authors read and approved the final manuscript.

\section{Competing interests}

The authors declare that they have no competing interests.

\section{Author details}

'Department of Plant Protection Biology, Swedish University of Agricultural Sciences, P.O. Box 102, SE-230 53 Alnarp, Sweden. ${ }^{2}$ Department of Forest Mycology and Plant Pathology, Swedish University of Agricultural Sciences, P.O. Box 7026, SE-750 07 Uppsala, Sweden. ${ }^{3}$ Department of Plant Breeding, Swedish University of Agricultural Sciences, P.O. Box, 101, SE-230 53 Alnarp, Sweden.

Received: 31 May 2016 Accepted: 13 September 2016

Published online: 23 September 2016

\section{References}

1. Thomma B. Alternaria spp.: from general saprophyte to specific parasite. Mol Plant Pathol. 2003;4:225-36.

2. Pelletier JR, Fry WE. Characterization of Resistance to Early Blight in Three Potato Cultivars:Incubation Period, Lesion Expansion Rate, and Spore Production. Phytopathology. 1989;79:511-7.

3. Agrios GN. Plant Pathology. 5th ed. London: Elsevier Academic Press; 2005. p. 454-5.

4. Pavek JJ, Corsini DL. Inheritance of resistance to warm-growing-season fungal diseases. Wallingford: Cab International; 1994.

5. Al-Mughrabi Kl. Efficacy of OxiDate for control of early blight (Alternaria solani) in potato storages. Plant Pathol. 2005;4:1-4.

6. Andersson B, Wiik L. Betydelsen av torrfläcksjuka (Alternaria ssp.) på potatis Slutrapport av SLF 0455031. 2008. http://www.lantbruksforskning.se/ projektbanken/betydelsen-av-torrflacksjuka-alternaria-ssp-pa-pot/?search= andersson\&page=1\&pub_year=2008\&app_year=\&category=

7. Edin E, Andersson B. The early blight situation in Sweden-species abundance and strobilurin sensitivity. PPO Special Rep. 2014:83-84

8. Milgroom MG, Peever TL. Population biology of plant pathogens - The synthesis of plant disease epidemiology and population genetics. Plant Dis. 2003;87:608-17.

9. Lourenco V, Rodrigues T, Campos AMD, Braganca CAD, Scheuermann KK, Reis A, Brommonschenkel SH, Maffia LA, Mizubuti ESG. Genetic Structure of the Population of Alternaria solani in Brazil. J Phytopathol. 2011;159:233-40.

10. Petrunak DM, Christ BJ. Isozyme Variability in Alternaria solani and A. alternata. Phytopathology. 1992:82:1343-7.

11. Weir TL, Huff DR, Christ BJ, Romaine CP. RAPD-PCR analysis of genetic variation among isolates of Alternaria solani and Alternaria alternata from potato and tomato. Mycologia. 1998;90:813-21.

12. van der Waals JE, Korsten L, Slippers B. Genetic diversity among Alternaria solani isolates from potatoes in South Africa. Plant Dis. 2004;88:959-64

13. Zhang F, Yang Z, Zhu J, Zhang H, Wei W. Population structure of Alternaria solani on potato in Hebei Province. Mycosystema. 2012;31:40-9.

14. Perez Martinez S, Snowdon R, Pons-Kuhnemann J. Variability of Cuban and international populations of Alternaria solani from different hosts and localities: AFLP genetic analysis. Eur J Plant Pathol. 2004;110:399-409.

15. Pasche JS, Piche LM, Gudmestad NC. Effect of the F129L mutation in Alternaria solani on fungicides affecting mitochondrial respiration. Plant Dis. 2005;89:269-78.

16. Luo Y, Ma ZH, Reyes HC, Morgan DP, Michailides TJ. Using real-time PCR to survey frequency of azoxystrobin-resistant allele G143A in Alternaria populations from almond and pistachio orchards in California. Pestic Biochem Physiol. 2007;88:328-36.

17. Rosenzweig N, Atallah ZK, Olaya G, Stevenson WR. Evaluation of Qol fungicide application strategies for managing fungicide resistance and potato early blight epidemics in Wisconsin. Plant Dis. 2008:92:561-8.

18. Vega B, Dewdney MM. Distribution of Qol Resistance in Populations of Tangerine-Infecting Alternaria alternata in Florida. Plant Dis. 2014;98:67-76.

19. Leiminger $\mathrm{JH}$, Adolf $\mathrm{B}$, Hausladen $\mathrm{H}$. Occurrence of the F129L mutation in Alternaria solani populations in Germany in response to Qol application, and its effect on sensitivity. Plant Pathol. 2014;63:640-50.
20. Edin E. Species specific primers for identification of Alternaria solani, in combination with analysis of the F129L substitution associates with loss of sensitivity toward strobilurins. Crop Prot. 2012;38:72-3.

21. Gannibal PB, Orina AS, Mironenko NV, Levitin MM. Differentiation of the closely related species, Alternaria solani and A-tomatophila, by molecular and morphological features and aggressiveness. Eur J Plant Pathol. 2014;139:609-23.

22. Zur G, Shimoni E, Hallerman E, Kashi Y. Detection of Alternaria fungal contamination in cereal grains by a polymerase chain reaction-based assay. J Food Prot. 2002;65:1433-40.

23. Vos P, Hogers R, Bleeker M, Reijans M, Vandelee T, Hornes M, Frijters A, Pot J, Peleman J, Kuiper M, Zabeau M. AFLP - a new technique for DNA-fingerprinting. Nucleic Acids Res. 1995;23:4407-14

24. Nei M, Li WH. Mathematical model for studying genetic variation in terms of restriction endonucleases. Proc Natl Acad Sci. 1979;76:5269-73.

25. Pavlicek A, Hrda S, Flegr J. FreeTree-freeware program for construction of phylogenetic trees on the basis of distance data and bootstrap jackknife analysis of the tree robustness. Application in the RAPD analysis of genus Frenkelia. Folia Biol. 1999;45:97-9.

26. Excoffier L, Smouse PE, Quattro JM. Analysis of molecular variance inferred from metric distances among DNA haplotypes - Application to human mitochondrial-DNA restriction data. Genetics. 1992;131:479-91.

27. Odilbekov F, Carlson-Nilsson U, Liljeroth E. Phenotyping early blight resistance in potato cultivars and breeding clones. Euphytica. 2014;197:87-97.

28. Franco J, Crossa J, Ribaut JM, Betran J, Warburton ML, Khairallah M. A method for combining molecular markers and phenotypic attributes for classifying plant genotypes. Theor Appl Genet. 2001;103:944-52.

29. Berbee ML, Payne BP, Zhang GJ, Roberts RG, Turgeon BG. Shared ITS DNA substitutions in isolates of opposite mating type reveal a recombining history for three presumed asexual species in the filamentous ascomycete genus Alternaria. Mycol Res. 2003;107:169-82.

30. Litvintseva AP, Marra RE, Nielsen K, Heitman J, Vilgalys R, Mitchell TG. Evidence of sexual recombination among Cryptococcus neoformans serotype A isolates in sub-Saharan Africa. Eukaryot Cell. 2003;2:1162-8.

31. Dodgson AR, Pujol C, Pfaller MA, Denning DW, Soll DR. Evidence for recombination in Candida glabrata. Fungal Genet Biol. 2005;42:233-43.

32. Stewart JE, Thomas KA, Lawrence CB, Dang H, Pryor BM, Timmer LM, Peever TL. Signatures of Recombination in Clonal Lineages of the Citrus Brown Spot Pathogen, Alternaria alternata sensu lato. Phytopathology. 2013;103:741-9.

33. Stall RE. An investigation of nuclear number in Alternaria solani. Am J Bot. 1958:45:657-9.

34. Torriani SFF, Brunner PC, McDonald BA, Sierotzki H. Qol resistance emerged independently at least 4 times in European populations of Mycosphaerella graminicola. Pest Manag Sci. 2009;65:155-62.

35. Rogers PM, Diversity and biology among isolate of Alternaria dauci collected from commercial carrot fields. ProQuest. 2007

36. Pasche JS, Gudmestad NC. Prevalence, competitive fitness and impact of the F129L mutation in Alternaria solani from the United States. Crop Prot. 2008:27:427-35

\section{Submit your next manuscript to BioMed Central and we will help you at every step:}

- We accept pre-submission inquiries

- Our selector tool helps you to find the most relevant journal

- We provide round the clock customer support

- Convenient online submission

- Thorough peer review

- Inclusion in PubMed and all major indexing services

- Maximum visibility for your research

Submit your manuscript at www.biomedcentral.com/submit
) Biomed Central 